\section{Qualitative methods of data analysis in psychology: an analysis of the literature}

\author{
María Jesús Carrera-Fernández
}

University of Barcelona, Spain

\section{Joan Guàrdia-Olmos}

University of Barcelona, Spain

\section{Maribel Peró-Cebollero}

University of Barcelona, Spain

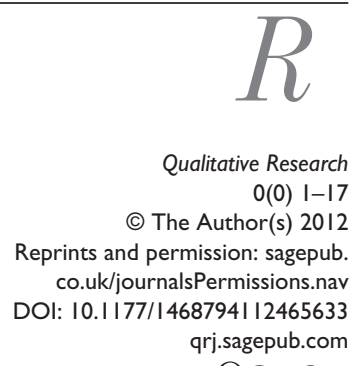

(9SAGE

\begin{abstract}
In this article, we present a general overview of the state of qualitative research in psychology by analyzing publications found in the Institute for Scientific Information's Web of Science database. Our objective is to provide a global perspective on the use of qualitative methods in data analysis and the frequency with which they are used in the journals. In total, 4840 articles were analyzed. We used bibliometrics methods to describe the publication patterns. We find a considerable increase throughout the 1990 s in the number of publications using qualitative methods. Specifically, content analysis, grounded theory and discourse analysis steadily increased. The most representative qualitative publication in psychology uses content analysis and is most likely published in a journal indexed in the Social Sciences edition of the Journal Citation Reports. The data that we have obtained seem to indicate that qualitative research publications will continue increasing in the coming years.
\end{abstract}

\title{
Keywords
}

data collection and management, psychology, qualitative, qualitative analysis, qualitative research, systematic reviews

Qualitative research is being published with increasing frequency in mainstream psychology journals (Madill and Gough, 2008), despite its continued exclusion from the

\footnotetext{
Corresponding author:

María Jesús Carrera-Fernández, Department of Methodology of the Behavioural Sciences, Faculty of Psychology, University of Barcelona, Passeig Vall de Hebron I7I, 08035 Barcelona, Spain.

Email:mcarrera@ub.edu
} 
most prestigious of these journals (Rennie et al., 2002). In the social sciences, the quantity of qualitative research being conducted and published is increasing rapidly (Elliot et al., 1999; Kidd, 2002). However, the volume of qualitative psychology research being produced is still modest when compared with the amount of quantitative research being published (Madill and Gough, 2008).

A growing number of researchers in psychology are beginning to use qualitative methods. However, the development of qualitative methodologies in psychology is being hindered by scepticism about their validity and, according to some editors, by the limited quantity of qualitative manuscripts being sent to the journals (Kidd, 2002). Some fields, such as anthropology and sociology, have a strong qualitative tradition. The historical development of qualitative research in these fields faced up to debates and controversies similar to those that subsequently occurred in psychology (Denzin and Lincoln, 2000; Kidd, 2002; Vidich and Lyman, 2000).

Qualitative methods have long been used in psychology research. Wilhelm Wundt (1921), who founded the first psychology laboratory, predicted that the field would have two branches. In one branch, psychology would be pursued as the study, in the laboratory, of elementary psychological functions, such as sensation and perception. The second branch of psychology would be devoted to the study of superior psychological functions beyond the level of individual consciousness (Marecek, 2003). The study of these functions required methods similar to the ones used in ethnology, history and anthropology (Cole, 1996). The first branch eventually became the most prominent; current psychology research has shown less interest in the second branch. However, a line of qualitative research has been developed incrementally by authors such as William James, Gordon Allport, Robert White, Leon Festinger and others (Marecek, 2003). Important contributions have been made to psychology by studies employing qualitative methodologies. Among the most important of these studies were those conducted by eminent psychologists such as Kurt Lewin, Henry Murray, Erik Erikson, Jean Piaget and others (Langenhove, 1995; Rogers, 2000). It is important to note that all these contributions are historical references in the field of psychology, which shows the relevance that qualitative methods have had in the development of this science.

In the 1980s and 1990s, the influence of postmodernism and post-structuralism caused a wave of qualitative methods to emerge in psychology (Madill and Gough, 2008). During this period, the strengths of qualitative methods were reassessed and their ability to access personal experience and understand its significance, their respect for cultural diversity and context, their ability to generate hypotheses and their capability to face topics in depth began to be considered valuable. Moreover, qualitative researchers made technological breakthroughs by developing software for qualitative analysis. Unfortunately, because of its rapid expansion, many researchers began to use qualitative methods mechanically. Although these methods are tools, they are not automatic (Charmaz, 2004). The new preference for qualitative methods was supported by the British Psychological Society's establishment, in 2005, of the Qualitative Methods in Psychology Section (Madill and Todd, 2002) and by a campaign for the establishment of a Qualitative Research Division in the American Psychological Association (APA) (Madill and Gough, 2008). 
The current state of qualitative research is heterogeneous. It is confusingly conceptualized as various sets of methods, some of which share common characteristics and some of which do not. No definitive typology has been established (Madill and Gough, 2008). We define qualitative research according to Schwandt (2001) as research in which the researcher trusts textual data more than numerical data and analyzes this data in its textual form instead of transforming it into numbers for analysis, with the objective of understanding the meaning of human action. The only annotation that we point at in this definition is that not only textual data but also visual, verbal, bodily, audio and spatial data are used (Reavey, 2011). However, the importance of the previous definition is that data are analyzed in their original dimension, without being previously transformed into numbers. Reavey (2011) criticizes qualitative researchers in psychology for not giving enough attention to this wider variety of modalities of data. This author described the reliance on the spoken or written words as a source of data and as a monomodal approach.

Although it seems obvious that qualitative research should be present in psychology because it allows investigators to approach problems that are hardly accessible in any other way, it is also obvious that the discipline values it less than quantitative research. There are several variables that influence this attitude, including the complexity of qualitative analysis. Qualitative research, like quantitative research, is not a simple and homogeneous phenomenon (Krahn et al., 1995). The expression 'qualitative research' covers multiple methods and theoretical approaches, not all of which are compatible with each other (Kidd, 2002). Moreover, there is little consensus on the preferable methods for analyzing qualitative data (Miles and Huberman, 1984).

Kidd (2002), Marchel and Owens (2007) and others have written reviews on the acceptance of qualitative research by several publications associated with the APA. Kidd found that, on average, only 1.3 percent of the manuscripts accepted by 15 APA journals in 1989, 1994 and 1999 involved qualitative research. Five of the analyzed journals never published a qualitative article. This was the case even though the number of qualitative studies generated by searches of the PsycINFO database was more than the doubled between 1989 and 1994 and more than doubled again between 1994 and 1999 (Kidd, 2002). The trend observed by Kidd supports the hypothesis that the amount of qualitative research being conducted is rapidly increasing in the social sciences (Elliot et al., 1999; Kidd, 2002; Strean, 1998).

Marchel and Owens performed a subsequent search of 57 journals associated with the APA and discovered that, out of the 96,379 articles published between 1950 (or the date of the first publication) and 2002, only 1248 were considered qualitative. This proportion $(1.29 \%)$ is similar to Kidd's (2002) findings.

Moreover, researchers use many different terms to refer to a large variety of approaches and qualitative methods (Denzin and Lincoln, 2000), which makes any attempt to analyze actual publications difficult. Some authors refer to formal theories, schools of thought, or movements, such as symbolic interactionism or feminism, as 'methodologies' (Carter and Little, 2007). Madill and Gough (2008) have created a comprehensive, but not exhaustive, list of the methods used to analyze qualitative data. They classify qualitative methods as discursive, thematic, structured, or instrumental. We have based our study on this list because we consider it the most complete and updated compilation 
available in the psychology field. Furthermore, it has been published in a recognized journal with a high impact factor.

Using the list compiled by these authors, we intend to review the studies that relied on these methods using bibliometric analysis. Over the decades, bibliometry has become a standard tool for scientific policy and research management. All significant compilations of scientific indicators depend, to a large extent, on publication statistics, citations and other results obtained through more sophisticated bibliometric techniques (Glänzel, 2003). Bibliometry is an interdisciplinary research strategy that has been widespread to almost all scientific fields. In this article, we provide a general overview of the use of qualitative analysis methods in psychology by conducting a bibliometric study of research publications.

\section{Method}

\section{Data collection}

We find the documents analyzed in this study via a database search of the Web of Science (WoS), which is the website of the Institute for Scientific Information (ISI), part of Thompson Scientific. We conducted the search in May 2011. We consulted the Science Citation Index (SCI), the Social Sciences Citation Index (SSCI) and the Arts and Humanities Citation Index (AHCI). The WoS is recognized as the most trustworthy indexing tool for scientific literature and provides access to articles from the most important areas of research in science and technology (Boyack et al., 2005). Our inclusion criterion required that specific keywords should appear in the topic field. The search was not limited according to the type of document or publication date. We searched for publications from any discipline. Once we obtained the search results, we used WoS's refine results feature to limit the results shown to those catalogued in the psychology subject area.

We used the keywords included on list of methods for analyzing qualitative data developed by Madill and Gough (2008). We employed this list because its structure was clear, and we believed it to be one of the most complete published lists. Using 32 keywords, we found 6283 publications that matched the search criteria.

\section{Data analysis}

To conduct the analysis, we codified the following variables: authors, number of authors, title, source, language, type of document, total number of citations, editor, publication year, thematic category and method.

We analyzed author productivity using Lotka's (1926) law, one of the main laws of bibliometry. Lotka observed that in any given field or scientific area, there are many authors who publish only one study and only a few prolific authors who contribute a large number of publications. This is also known as the inverse square law because it takes the number of authors who have contributed a single study and predicts how many authors have published $x$ studies, which is proportional to $1 / x^{2}$. For example, if we know how many authors have published a single study in a given field, we can predict how many authors would have published twice, according to the formula $y_{x}=c \times 1 / x^{2}$, were 
$y_{x}$ is the number of authors with $x$ publications, $c$ is the number of authors with a single publication and $x$ is the number of publications itself. As the number of publications increases, the number of authors who have published $x$ articles decreases (Andrés, 2009). This productivity pattern does not seem to depend on the science in which it is applied. The only caveat for Lotka's law is that the period of time over which the data are gathered must be at least 10 years (Andrés, 2009; Potter, 1981). According to this pattern, an author production profile is not randomly distributed. In fact, up to a point, the more articles produced by an author the more likely he is to produce others. Therefore, productivity is related not to the number of articles published by an author but to its logarithm. Lotka's law has been widely studied, and as a result, there are different methods for calculating the specific coefficients and assessing the degree of adjustment (Loughner, 1992; Nicholls, 1989; Pao, 1985). To analyze the search results, we used Excel 2007 and PASW Statistics 18 for Windows.

\section{Results}

\section{Qualitative methods of data analysis in psychology: an overview}

In Table 1, we show the number of publications found for each keyword, specifying how many of them related to psychology. We observe that 13.87 percent of the publications

Table I. Total number of publications

\begin{tabular}{lrrc}
\hline Keyword in TOPIC & Publications & $\begin{array}{c}\text { Publications } \\
\text { in psychology }\end{array}$ & Percentage \\
\hline Conversation analysis & \multicolumn{1}{c}{ 1201 } & 246 & 20.48 \\
Discourse analysis & 3435 & 668 & 19.45 \\
Metaphorical analysis & 24 & 7 & 29.17 \\
Psychoanalytically informed analysis & 1 & 0 & 0 \\
Semiotic analysis & 243 & 15 & 6.17 \\
Analytic induction & 72 & 14 & 19.44 \\
Framework analysis & 199 & 19 & 9.55 \\
Grounded theory & 4629 & 743 & 16.05 \\
Interpretative phenomenological & 374 & 201 & 53.74 \\
analysis & & & \\
Template analysis & 82 & 9 & 10.98 \\
Thematic analysis & 1865 & 243 & 13.03 \\
Theory-led thematic analysis & 1 & 0 & 0 \\
Attributional analysis & 235 & 178 & 75.74 \\
Comprehensive process analysis & 18 & 11 & 61.11 \\
Consensual qualitative research & 138 & 104 & 75.36 \\
Content analysis & 11,888 & 1827 & 15.37 \\
Logical analysis & 529 & 54 & 10.21 \\
Protocol analysis & 1267 & 157 & 12.39 \\
Q-methodology & 287 & 61 & 21.25 \\
\hline
\end{tabular}


Table I. (Continued)

\begin{tabular}{lrcr}
\hline Keyword in TOPIC & Publications & $\begin{array}{l}\text { Publications } \\
\text { in psychology }\end{array}$ & Percentage \\
\hline Repertory grid analysis & 30 & 8 & 26.67 \\
Task analysis & 972 & 306 & 31.48 \\
Action research & 3662 & 404 & 11.03 \\
Co-operative inquiry & 28 & 1 & 3.57 \\
Ethnography & 7086 & 308 & 4.35 \\
Ethnomethodology & 528 & 67 & 12.69 \\
Feminist research & 512 & 83 & 16.21 \\
Media framing analysis & 3 & 2 & 66.67 \\
Narrative analysis & 760 & 115 & 15.13 \\
Phenomenological methods OR & 1486 & 304 & 20.46 \\
phenomenological analysis & 1145 & 82 & 7.16 \\
Process evaluation & 2560 & 43 & 1.68 \\
Rapid assessment & 45 & 3 & 6.67 \\
Visual methodologies OR visual & & & 13.87 \\
methodology & 45,305 & 6283 & \\
Total & & & \\
\hline
\end{tabular}

that used qualitative research methods belong to the psychology area. We verify that the most commonly used methods in psychology publications are content analysis (1827), grounded theory (743), discourse analysis (668), action research (404), ethnography (308), task analysis (306) and phenomenological methods or phenomenological analysis (304). These are also the most commonly used methods in all the disciplines that appeared in the search results.

Also interesting is the percentage that psychology publications represent within the total number of publications for each method. This indicates either the suitability of the method to the object of study or the appropriation by psychological science of a particular method. The method with the highest percentage of psychology documents is attributional analysis (75.74\%) with 178 psychology publications, closely followed by consensual qualitative research $(75.36 \%)$ with 104 publications, media framing analysis $(66.67 \%)$ with only 2 publications, comprehensive process analysis $(61.11 \%)$ with 11 publications and interpretative phenomenological analysis $(53.74 \%)$ with 201 publications. According to these weighted percentages, the most typical methods in psychology tend to be those that Madill and Gough classify as structured. Such methods are characterized by their ability to provide procedural clarity (Madill and Gough, 2008). They define a priori areas of analytic interest, prepare codification schemes, use prior theory to interpret the data, and at times, even transform qualitative data into numbers (Madill and Gough, 2008).

After this initial analysis, the list was refined to eliminate the output that appeared in the results of more than one distinct search (i.e. the same article could be found by both the conversation analysis and the discourse analysis search), which doubled or even 
tripled the presence of some of the documents. We select the publications that use more than one method to determine whether there was any combination of two or three methods that occurred more frequently. We find that, of the 201 publications brought up by the interpretative phenomenological analysis search, all but two were also brought up by the phenomenological methods search. We therefore combined the results of the two searches. We did not find any other predominant combination. To account for the duplicated publications, we respect their classification into distinct methods, generating a new category called 'multimethod'. In this way, the total number of publications in psychology was reduced from 6283 to 5861 .

\section{Global publication output}

Of the 5861 publications generated by the searches, 4840 are classified as articles by the WoS. We conduct the analyses that follow on this latter group of documents, which represent 82.6 percent of the total.

The articles were included in the analysis regardless of the language in which they were published. English language publications predominated and were followed, after a significant gap, by publications in German. English is the primary language used in many disciplines. Because the majority of the journals listed in the ISI are published in English, it is appropriate to expect English to predominate (Chiu and Ho, 2007).

The annual production of articles employing qualitative methods has increased over the years. We observe in our search results that, in the 1990s, a considerable increase in published articles occurred, from 12 in 1990 to 171 in 1999. This increase continued into the 2000s, with 529 articles being published in 2010. Figure 1 displays the growing publication count, beginning with the first publication and ending with the data from 2010 . We excluded articles published in 2011 from the chart because we do not have complete data for this year.

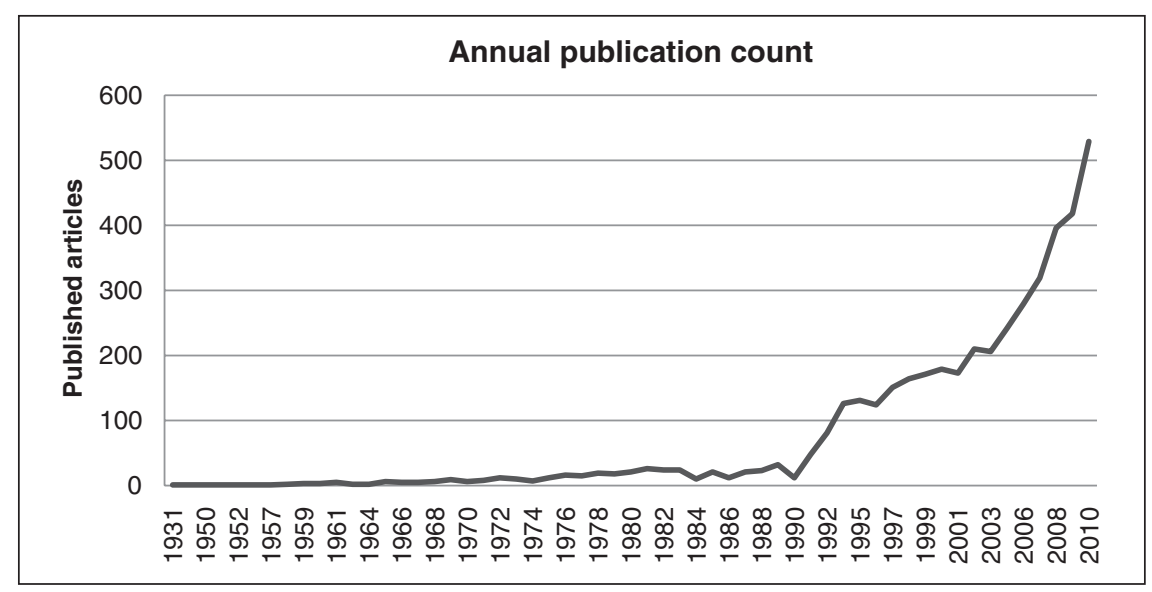

Figure I. Articles published from $193 \mathrm{I}$ to 2010. 


\section{Publication count by method: temporal evolution}

Of special interest to our study is how the publication count of each method has changed over the years. We examined the methods for which more than 100 articles had been published.

The methods most frequently used in psychology research are content analysis (1454 articles), grounded theory (577), discourse analysis (460), action research (271) and phenomenological methods (252), considering the amount of time that has passed between the publication of the first qualitative analysis study and 2010. ${ }^{1}$ We did not include articles published before 1970 because they represented a very small percentage of the total publications. Content analysis is by far the most commonly used method. In the five most frequently used methods, we observe a growing trend in the number of their publications, most noticeable in the case of content analysis and grounded theory.

Because of the protracted period of time we have covered in this article and because each of the methods began to be published at a different date, we perform an analysis considering the years since a method's first publication and the average number of articles published on that method each year, as we have summarized in Table 2. We notice that, beginning in the 1950 s, three to four new methods are added every decade. The highest number of new methods appears in the 1970s.

The three methods with the highest average of yearly publications are also the three with the highest publication count. However, although both phenomenological methods and action research have a long history of publication, they have a low annual average. This is in contrast with the evolution of methods such as consensual qualitative research, which has a short history but a higher annual average. In Table 2, we organize the methods in ascending order; the methods with the earliest publication date appear first. In the last column, we show what proportion of a method's articles has appeared in the last decade, although the total number of publications should also be considered. The most current methods, that is, the ones presenting a higher proportion of published articles after 2000, and at least 50 published articles over the last decade are consensual qualitative research, grounded theory, narrative analysis, phenomenological methods, thematic analysis, conversation analysis and discourse analysis. Only the rate of publication of attributional analysis decreased.

\section{Publication count by subject category}

The number of articles classified in more than one subject category amounted to 59.59 percent of the total articles. In addition, 45.89 percent of the total is classified in one or more areas exclusively within psychology, which indicates that, although psychology is a multidisciplinary field closely related to other disciplines, much of its content is specific to psychology. Figure 2 displays the most common areas of psychology and the number of articles belonging to each of them.

We find frequent associations between method and subject. Logically, the most commonly used method, content analysis, is also the one shared between the most subject areas. It is interesting to note the particularities of certain methods, such as the use of the attributional analysis in social psychology, task analysis in applied psychology and phenomenological methods and thematic analysis in clinical psychology. 
Table 2. Evolution of methods

\begin{tabular}{|c|c|c|c|c|c|c|}
\hline Method & $\begin{array}{l}\text { First } \\
\text { article }\end{array}$ & $\begin{array}{l}\text { Years of } \\
\text { evolution } \\
\text { since first } \\
\text { publication }\end{array}$ & $\begin{array}{l}\text { Total } \\
\text { articles } \\
\text { published }\end{array}$ & $\begin{array}{l}\text { Average } \\
\text { articles } \\
\text { per year }\end{array}$ & $\begin{array}{l}\text { Articles } \\
\text { published } \\
\text { between } 2000 \\
\text { and } 201 \mathrm{I}\end{array}$ & $\begin{array}{l}\% \text { of } \\
\text { articles } \\
\text { published } \\
\text { since } 2000\end{array}$ \\
\hline $\begin{array}{l}\text { Phenomenological } \\
\text { methods }\end{array}$ & 1931 & 80 & 265 & 3.31 & 212 & 80.00 \\
\hline Action research & 1950 & 61 & 276 & 4.52 & 177 & 64.13 \\
\hline Content analysis & $195 \mid$ & 60 & 1505 & 25.08 & 878 & 58.34 \\
\hline Thematic analysis & 1958 & 53 & 202 & 3.81 & 161 & 79.70 \\
\hline Logical analysis & 1961 & 50 & 39 & 0.78 & 20 & 51.28 \\
\hline Q-methodology & 1961 & 50 & 51 & 1.02 & 31 & 60.78 \\
\hline Task analysis & 1965 & 46 & 237 & 5.15 & 106 & 44.73 \\
\hline Ethnography & 1967 & 44 & 194 & $4.4 I$ & 112 & 57.73 \\
\hline Attributional analysis & 1970 & $4 I$ & 153 & 3.73 & 49 & 32.03 \\
\hline Process evaluation & 1975 & 36 & 62 & 1.72 & 44 & 70.97 \\
\hline Ethnomethodology & 1976 & 35 & 22 & 0.63 & 12 & 54.55 \\
\hline Grounded theory & 1977 & 34 & 606 & 17.82 & 504 & 83.17 \\
\hline Rapid assessment & 1977 & 34 & 38 & 1.12 & 18 & 47.37 \\
\hline Discourse analysis & 1978 & 33 & 475 & 14.39 & 339 & 71.37 \\
\hline Protocol analysis & 1978 & 33 & 122 & 3.70 & 55 & 45.08 \\
\hline Conversation analysis & 1979 & 32 & 142 & 4.44 & 105 & 73.94 \\
\hline Repertory grid analysis & 1979 & 32 & 6 & 0.19 & 2 & 33.33 \\
\hline Feminist research & 1981 & 30 & 41 & 1.37 & 18 & 43.90 \\
\hline Semiotic analysis & 1984 & 27 & 9 & 0.33 & 5 & 55.56 \\
\hline Metaphorical analysis & 1985 & 26 & 7 & 0.27 & 3 & 42.86 \\
\hline Narrative analysis & 1987 & 24 & 90 & 3.75 & 73 & 81.11 \\
\hline Framework analysis & 1992 & 19 & 17 & 0.89 & 13 & 76.47 \\
\hline Analytic induction & 1993 & 18 & 12 & 0.67 & 6 & 50.00 \\
\hline $\begin{array}{l}\text { Comprehensive } \\
\text { process analysis }\end{array}$ & 1994 & 17 & 6 & 0.35 & 4 & 66.67 \\
\hline Visual methodologies & 2000 & 11 & 3 & 0.27 & 3 & 100 \\
\hline $\begin{array}{l}\text { Consensual qualitative } \\
\text { research }\end{array}$ & 2001 & 10 & 83 & 8.30 & 83 & 100 \\
\hline Template analysis & 2007 & 4 & 6 & 1.50 & 6 & 100 \\
\hline Media framing analysis & 2009 & 2 & 2 & 1.00 & 2 & 100 \\
\hline
\end{tabular}

\section{Authors}

The total number of authors who contributed in any way to the analyzed articles was 10,709. We counted 4235 first authors. Many of them have published more than once. The number of authors of any one article ranged between 1 and 23. The majority of articles has two authors $(1587 ; 32.8 \%)$, followed in frequency by those with a single author $(1356 ; 28.0 \%)$, three authors $(907 ; 18.7 \%)$, four authors $(516 ; 10.7 \%)$, five authors $(217 ; 4.5 \%)$ and those with more than six authors $(257 ; 5.2 \%)$, indicating that collaborative authorship is common in this field. 


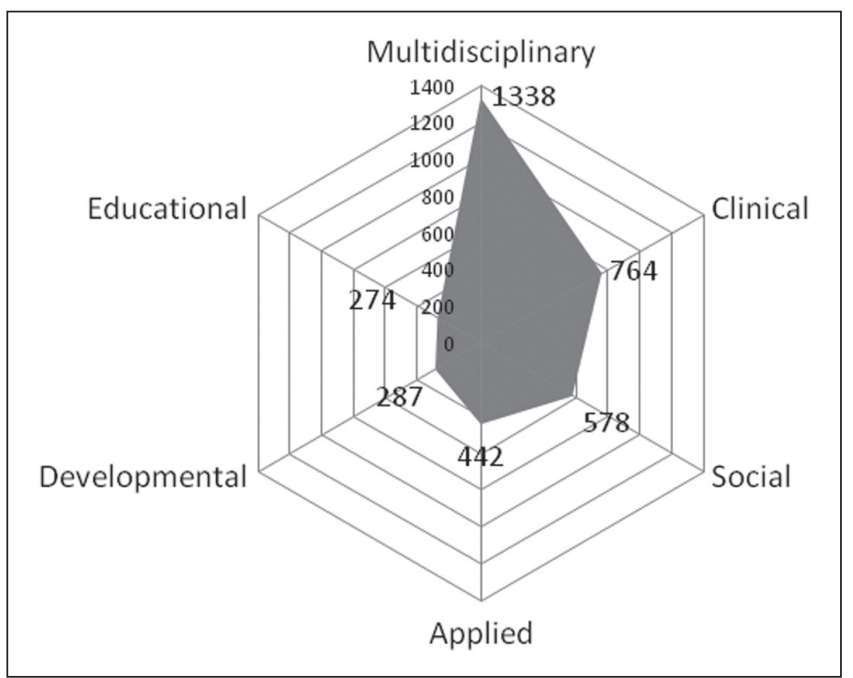

Figure 2. Main subjects of published articles.

Using Lotka's law, we estimate that $n=3.773$ and $C=0.909$. To determine whether the data predicted using Lotka's law fitted the observed distribution, we used the Kolmogorov-Smirnov test. The data reveal a $D_{\max }=0.008$, which we compare to the critical value of 0.0249 . These results justify the rejection of a null hypothesis. We therefore conclude that the author productivity of qualitative methods publications follows Lotka's law. This means that productivity per author is not distributed randomly, but the more articles produced by an author, the more likely this author is to produce others. It appears to become progressively easier to publish once an author has published a large number of articles.

\section{Journals}

We observe a wide distribution of articles related to qualitative methods, analyzing publications from 544 different journals. Among them, Discourse and Society, Sex Roles and the Journal of Health Psychology led the list of journals with the highest number of publications that used qualitative methods. It is interesting to note that each of these journals has a specific focus (communication, gender and health, respectively), meaning that they are not only qualitative or methodology oriented. To explain what makes them so attractive for qualitative articles, we consider how these journals present themselves:

Discourse and Society is a leading international peer-reviewed journal whose major aim is to publish outstanding research at the boundaries of discourse analysis and the social sciences. It focuses on explicit theory formation and analysis of the relationships between the structures of text, talk, language use, verbal interaction or communication, on the one hand, and social, political or cultural micro- and macrostructures and cognitive social representations, on the other. Retrieved from http://das.sagepub.com/ 
Sex Roles: A Journal of Research is an interdisciplinary behavioral science journal offering a feminist perspective. It publishes original research reports and review articles that illuminate the underlying processes and consequences of gender role socialization, gendered perceptions and behaviors, and gender stereotypes. The range of topics is broad, extending to gender issues in employment and work environments; interpersonal relationships $[\ldots]$ or methodological issues in gender research. All papers consider the possibility of gender differences in reporting the results of their research. Retrieved from http://www.springer.com/psychology/personality + $\% 26+$ social+psychology/journal/11199

Journal of Health Psychology is a leading international peer reviewed journal that aims to support and help shape research in health psychology from around the world. It provides a platform for traditional empirical analyses as well as more qualitative and/or critically oriented approaches. It also addresses the social contexts in which psychological and health processes are embedded. Retrieved from http://hpq.sagepub.com/

Clearly, in Discourse and Society, priority is given to discourse analysis. The Journal of Health Psychology is presented as being open to more qualitative approaches in general. In Sex Roles, the editor does not express any methodological preferences.

Among the journals that published more than 50 qualitative articles, we find that the vast majority of them are indexed in the Social Sciences edition of the Journal Citation Reports (JCR). In fact, the first journal indexed in the Sciences edition, Psycho-Oncology, is sixth on our list, after the top three and the Journal of Community and Applied Social Psychology and Feminism and Psychology. It should also be pointed out that the impact factor of the journals that have published more qualitative articles tends to be low, though is reasonable considering they are journals specific to the field of psychology. Among those journals, PsychoOncology has the highest impact factor, precisely the journal indexed in Sciences.

When we analyze the predominant method employed in these journals, we find that, although none of them publish any method exclusively, each journal has distinct tendencies. In addition to Discourse and Society's preference for discourse analysis $(65.99 \%$ articles on this method), others, such as Ergonomics, show a tendency towards task analysis (78.12\%). Sex Roles, meanwhile, seems to prefer content analysis $(75.78 \%)$. Similarly American Behavioral Scientist also prefers content analysis (57.14\%). It appears that action research is strongly represented in the qualitative publications accepted by the American Journal of Community Psychology (56.66\%). Indeed, the philosophy behind this method and the interests of the journal perfectly coincide.

\section{Citation analysis}

The number of times each article had been cited ranged between 0 and 518. Most of the articles have fewer than 10 citations $(3702 ; 76.49 \%)$, and many of them have no citations $(1101 ; 22.75 \%)$. Only 34 articles have more than 100 citations $(0.70 \%)$. The three most cited articles are from 1970, 1988 and 1998. The first two use the same method, attributional analysis. The high number of citations these articles received might be related to their publication in the Journal of Personality and Social Psychology, an APA publication with a high impact factor (4.732 in 2009). 
There is a considerable increase in citations in the 1980s, although in an analysis of citation frequency by decade, we observe that the number of citations peaks in the 1990s (20,740 cites in this decade). However, the highest citation average per article occurred in the 1980s (19.65 mean citations). The citation average per article decreased in the 1990s (16.32) and 2000s (5.18), probably because of the wider distribution, caused by the increasing number of articles.

\section{Conclusions and discussion}

We find that the increase in publications demonstrated in this study supports the hypothesis that the amount of qualitative research being conducted and published is rapidly increasing in the social sciences (Elliot et al., 1999; Kidd, 2002). This increase, however, might be characteristic of all disciplines; in the past few decades, an exponential increase in the number of published articles has occurred.

We confirm that the number of psychology publications employing qualitative methods has increased, with a particularly noticeable increase in the 1990s. The increase in the 1990s corresponds to what Madill and Gough (2008) consider the second wave of qualitative methods in psychology, ushered in by the importation of postmodernist and poststructuralist perspectives during the 1980s and early 1990s, and an interest in discourse or text. The number of qualitative articles published has increased every year, including 2010. The methods that proved most publications count were content analysis, grounded theory, discourse analysis, phenomenological methods and action research. Including a broad variety of terms in the search criteria allowed us to cover a wide view of qualitative research, making possible a longitudinal review of the publication count of each method.

Because we have not limited our survey to journals associated with the APA, we cannot compare our results with those obtained by Kidd (2002) and Marchel and Owens (2007). However, it is clear that the trend found by Kidd in PsycINFO, in which the number of qualitative articles doubled between 1989 and 1994 and again between 1994 and 1999, is even more noticeable in the WoS during the same period.

We can say that the most representative qualitative publication in psychology is an article written in the English language by two authors that uses content analysis method. This representative article belongs to the field of multidisciplinary psychology in addition to being classed in another thematic area, which might be health, education, communication, law, management or environment. The article is most likely published in a journal indexed in the Social Sciences edition of the JCR. However, although this characterization seems curious, we should not forget that one of the enriching aspects of qualitative research is its respect for and its interest in diversity. Even though content analysis is the more frequently published method, it is important not to give priority to it but choose a method from among the wide range available that suits a study's particular research objectives.

Among the journals that publish qualitative research, Discourse and Society, Sex Roles and the Journal of Health Psychology stood out, although the data reveal a broad distribution of publications across hundreds of journals. The great majority of the journals analyzed in this article are indexed in the Social Sciences edition of the 
JCR. However, the journal Psycho-Oncology, which is indexed in Sciences, stands out for having progressively increased its acceptance of qualitative publications and for having a higher impact factor than the Social Sciences journals. It is striking that, among the journals that publish qualitative research in psychology with the highest frequency, there are none of a methodological nature. It is possible that this is because of the classification system employed by ISI, which conditioned our search, although it is also possible that it reflects the positivist and post-positivist paradigms that still prevail in psychology, at least in WoS publications. Probably the fact that structured methods are the most typical methods in psychology is due to the extensive influence of these paradigms in psychology, like a legacy of the positivism. The broad use of structured methods coincides with the concept that various authors have called methodolatry (Chamberlain, 2000). Historical reasons for this relate to the dominance of behaviourism, a strong emphasis on being objective and the pre-eminence of measurement (Chamberlain, 2000). Given that structured methods even get to transform qualitative data into numbers, it is probable that these methods make the researcher feel being in the right direction and being more objective, just what methodolatrists are looking for. Furthermore, the fact of having a priori codification schemes and using prior theory to interpret the data avoids having to deal with epistemological and theoretical perspectives.

However, it has been interesting for us to observe which methods are more 'alive' at the present time, or in other words, which methods are more currently being used and which ones are emerging. The methods evolution (Table 2) appears to show a resurgence of the interest in the experience in a wider sense, with methods that Madill and Gough (2008) classified as instrumentals (phenomenological methods, narrative analysis, visual methodologies and media framing analysis). This coincides with the growing interest of psychology in analyzing visual materials (Madill and Gough, 2008; Reavey, 2011) and other types of data.

This study had several limitations. We relied on the WoS because we consider it the most complete resource, though it is not the only database in which journals publishing qualitative research can be found. Therefore, the results of this study show the panorama that the WoS allows us to see of the qualitative publications in psychology. It is evident that the way in which the WoS classifies a publication determines the results we have obtained in all aspects: the method, subject category and so on. The WoS even considers if the theoretical and methodological framework of an article is from within the domain of psychology, something that is a difficult task given the wide field of study of this science and the emergence of new objects of psychological research.

We also limited our research to the list of methods of analysis created by Madill and Gough (2008), which is not exhaustive, and it is possible that more distinct names can be used to refer to qualitative methods. Finally, it was necessary that our keywords appear in the topic field. Because of the great quantity of publications that appeared in the search results, our ability to review the content of each of them in detail was limited. The results therefore depended on how ISI classifies each article. It is possible that not all the articles included in the analysis coincide with what we consider qualitative research. All this has probably influenced the results, including 
content analysis result as the more frequently published method. Under the concept content analysis, there are many different approaches, some of them with characteristics that are mainly quantitative, based on frequency analysis, cluster analysis and other similar techniques. It is necessary to read these results from this point of view, taking into account that probably not all content analysis (or other methods) publications are qualitative.

We conclude by noting that there are still fewer qualitative publications in psychology than quantitative ones. We do not know whether the increase in qualitative publications will close the gap or whether quantitative publications will also experience a general increase. Within qualitative research, new questions emerge more frequently than new answers, the ethical risks are considerable (Stake, 2010), the cost is high (Silverman, 2000), the studies take much longer to complete and the researcher has fewer opportunities for performing multiple analyses of the same data set. It is probable that all these have an impact on the volume of articles that are submitted for publication.

It is also important to remember that working with a certain type of data regarded as qualitative, such as textual, visual, verbal, audio, bodily or spatial, or using qualitative techniques to gather data, is not what makes research qualitative. Rather, it is the manner in which the data is approached, the way in which they are analyzed and understood, that determines with more precision whether an investigation is qualitative or not. Qualitative researchers still have much to accomplish to guarantee the quality of their research, such as establishing criteria that are not simply adaptations of quantitative ones and that can be applied to any method. There have been significant progresses in this sense. Some researchers have contributed on the aspect of quality in qualitative research, for example, Morrow (2005), Tracy (2010) and more specifically, Parker (2004), among others. Parker raises some very interesting questions and criteria for the qualitative research in psychology. The challenge lies in extending these criteria to psychological journals with impact factor, to promote that, if necessary, they modify their requirements and do not apply totally unrelated criteria to qualitative research in their revisions.

In summary, in this article, we intended to provide a general overview of the range of publications in psychology that employ qualitative methods and describe their evolution. The data that we have obtained seem to indicate that publications of such research will increase in the coming years. The evaluation and synthesis of qualitative research is an increasingly urgent topic, its need being especially pressing in areas such as health (Carter and Little, 2007; Pound et al., 2005). In the current context, where number of publications and impact factors are increasingly being held forth in many settings as determinants of researchers holding their positions, there is often little encouragement to undertake qualitative research. Particularly, in medical research settings, where qualitative journals reflect very poorly against the high-impact-factor medical journals that they are compared with.

In psychology, qualitative investigation has much to offer. As Marecek (2003) affirms, pluralism and openness can help psychologists perform better than they do; with a wider range of accepted research options, investigators will be better able to choose the method that best suits their research objective. 


\section{Funding}

This work was partially supported by the Comissionat per a Universitats i Recerca from the Generalitat de Catalunya (Departament d'Innovació, Universitats i Empresa) and the European Social Fund.

\section{Acknowledgements}

We thank our colleagues Ana Andrés and Georgina Guilera for their contributions to this article.

\section{Note}

1. Detailed information is available on http://161.116.99.113/cuestionario/Qualitative Research Tables.html

\section{References}

Andrés A (2009) Measuring Academic Research: How to Undertake a Bibliometric Study. Oxford: Chandos Publishing.

Boyack KW, Klavans R and Börner K (2005) Mapping the backbone of science. Scientometrics 64(3): 351-374.

Carter SM and Little M (2007) Justifying knowledge, justifying method, taking action: epistemologies, methodologies and methods in qualitative research. Qualitative Health Research 17(10): 1316-1328.

Chamberlain K (2000) Methodolatry and qualitative health research. Journal of Health Psychology 5(3): 285-296.

Charmaz K (2004) Premises, principles, and practices in qualitative research: revisiting the foundations. Qualitative Health Research 14(7): 976-993.

Chiu WT and Ho YS (2007) Bibliometric analysis of tsunami research. Scientometrics 73(1): $3-17$.

Cole M (1996) Cultural Psychology: A Once and Future Discipline. Cambridge, MA: Harvard University Press.

Denzin NK and Lincoln YS (2000) Introduction: the discipline and practice of qualitative research. In: Denzin NK and Lincoln YS (eds) Handbook of Qualitative Research. Thousand Oaks, CA: Sage, 1-29.

Elliot R, Fischer CT and Rennie DL (1999) Evolving guidelines for publication of qualitative research studies in psychology and related fields. British Journal of Clinical Psychology 38: 215-229.

Glänzel W (2003) Bibliometrics as a Research Field: A Course on Theory and Application of Bibliometric Indicators (course handouts). Available at: http://nsdl.niscair.res.in/bitstream/123456789/968/1/

Kidd SA (2002) The role of qualitative research in psychological journals. Psychological Methods 7(1): 126-138.

Krahn GL, Hohn MF and Kime C (1995) Incorporating qualitative approaches into clinical child psychology research. Journal of Clinical Child Psychology 24(2): 204-213.

Langenhove LV (1995) The theoretical foundations of experimental psychology and its alternatives. In: Smith JA, Harre R and Langenhove LV (eds) Rethinking Psychology. Thousand Oaks, CA: Sage, 10-23.

Lotka AJ (1926) The frequency distribution of scientific productivity. Journal of the Washington Academy of Sciences 16(12): 317-323.

Loughner W (1992) Lotka law and the Kolmogorov-Smirnov test: an error in calculation. Journal of the American Society for Information Science 43(2): 149-150. 
Madill A and Gough B (2008) Qualitative research and its place in psychological science. Psychological Methods 13: 254-271.

Madill A and Todd Z (2002) Proposal to the Council of the British Psychological Society for the formation of a new section of the society on 'Qualitative Methods in Psychology'. Available at: http://biblioteca.universia.net/html_bura/ficha/params/title/proposal-to-the-council-of-thebritish-psychological-society-for/id/34469951.html

Marchel C and Owens S (2007) Qualitative research in psychology: could William James get a job? History of Psychology 10(4): 301-324.

Marecek J (2003) Dancing through minefields: toward a qualitative stance in psychology. In: Camic PM, Rhodes JE and Yardley L (eds) Qualitative Research in Psychology: Expanding Perspectives in Methodology and Design. Washington, DC: American Psychological Association, 49-69.

Miles MB and Huberman AM (1984) Qualitative Data Analysis. Beverly Hills, CA: Sage.

Morrow SL (2005) Quality and trustworthiness in qualitative research in counseling psychology. Journal of Counseling Psychology 52(2): 250-260.

Nicholls PT (1989) Bibliometric modeling processes and the empirical validity of Lotka law. Journal of the American Society for Information Science 40(6): 379-385.

Pao ML (1985) Lotka's law: a testing procedure. Information Processing \& Management 21(4): $305-320$.

Parker I (2004) Criteria for qualitative research in psychology. Qualitative Research in Psychology 1(2): $95-106$.

Potter J (1981) The development of social psychology: consensus, theory and methodology in the British Journal of Social and Clinical Psychology. British Journal of Social Psychology 20(4): 249-258.

Pound P, Britten N, Morgan M, et al. (2005) Resisting medicines: a synthesis of qualitative studies of medicine taking. Social Science \& Medicine 61(1): 133-155.

Reavey P (2011) The return to experience: psychology and the visual. In: Reavey P (ed.) Visual Methods in Psychology. Hove: Psychology Press, 1-13.

Rennie DL, Watson KD and Monteiro AM (2002) The rise of qualitative research in psychology. Canadian Psychology 43: 170-190.

Rogers AG (2000) When methods matter: qualitative research issues in psychology. Harvard Educational Review 70(1): 75-85.

Schwandt TA (2001) Dictionary of Qualitative Inquiry (2nd Edition). Thousand Oaks, CA: Sage.

Silverman D (2000) Doing Qualitative Research. London: Sage.

Stake RE (2010) Qualitative Research: Studying How Things Work. New York: Guilford.

Strean WB (1998) Possibilities for qualitative research in sport psychology. Sport Psychologist 12: $333-345$.

Tracy SJ (2010) Qualitative quality: eight 'big-tent' criteria for excellent qualitative research. Qualitative Inquiry 16(10): 837-851.

Vidich AJ and Lyman SM (2000) Qualitative methods: their history in sociology and anthropology. In: Denzin NK and Lincoln YS (eds) Handbook of Qualitative Research. Thousand Oaks, CA: Sage, 37-84.

Wundt W (1921) Elements of Folk Psychology. London: Allen \& Unwin.

\section{Biographical notes}

María Jesús Carrera-Fernández is a research fellow and member of the research team about Advanced Statistical Techniques Applied to Psychology at University of Barcelona Faculty of Psychology in Barcelona, Spain. 
Joan Guàrdia-Olmos, $\mathrm{PhD}$, is a professor and coordinator of the research team about Advanced Statistical Techniques Applied to Psychology at University of Barcelona Faculty of Psychology in Barcelona, Spain.

Maribel Peró-Cebollero, $\mathrm{PhD}$, is a researcher and member of the research team about Advanced Statistical Techniques Applied to Psychology at University of Barcelona Faculty of Psychology in Barcelona, Spain. 